
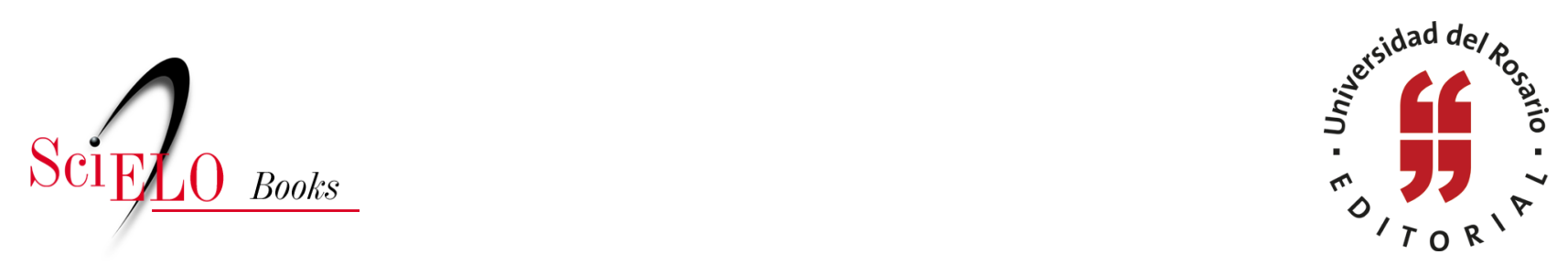

\title{
1. Aproximación al estudio del daño extrapatrimonial en la responsabilidad civil derivada del daño ambiental
}

\author{
Fernando Andrés Pico Zúñiga
}

\section{SciELO Books / SciELO Livros / SciELO Libros}

PICO ZÚÑIGA, F.A. Aproximación al estudio del daño extrapatrimonial en la responsabilidad civil derivada del daño ambiental. In: AMPARO RODRÍGUEZ, G., and VARGAS CHAVES, I., ed. Perspectivas de responsabilidad por daños ambientales en Colombia [online]. Bogotá: Editorial Universidad del Rosario, 2015, pp. 13-28. Textos de Jurisprudencia collection. ISBN: 978-958-738-644-8. https://doi.org/10.7476/9789587386448.0002.

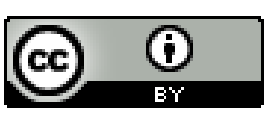

All the contents of this work, except where otherwise noted, is licensed under a Creative Commons Attribution 4.0 International license.

Todo o conteúdo deste trabalho, exceto quando houver ressalva, é publicado sob a licença Creative Commons Atribição 4.0.

Todo el contenido de esta obra, excepto donde se indique lo contrario, está bajo licencia de la licencia $\underline{\text { Creative }}$ Commons Reconocimento 4.0 . 


\section{Aproximación al estudio del daño extrapatrimonial en la responsabilidad civil derivada del daño ambiental}

Fernando Andrés Pico Zúñiga*

\section{Introducción}

La protección del medio ambiente es fundamental. Los tiempos actuales revelan, a través de fenómenos como el calentamiento global, las fuertes implicaciones de la contaminación en el ambiente y, en consecuencia, exigen que los Estados, las naciones, los pueblos y las personas reciban y se involucren con mayor responsabilidad, más allá de la estrictamente jurídica, en la salvaguardia del entorno natural con el que cuentan (Corte Constitucional de Colombia - CCC-, Sentencia C-632/11).

Los elementos materiales del ambiente son indudablemente trascendentales para la satisfacción de las necesidades del hombre y su desenvolvimiento presente y futuro dentro de la vida (Declaración de Río sobre el Medio Ambiente y el Desarrollo, 1992, principio 30; viI Protocolo de 1996 relativo al Convenio sobre la Prevención de la Contaminación del Mar por Vertimiento de Desechos y otras Materias). De ahí que la protección jurídica de los bienes corpóreos de la naturaleza sea tan relevante, en la medida en que no solo se dirige a preservar los derechos que recaen sobre la integridad física de las cosas en sí mismas consideradas —el agua, el aire, la tierra, etc.—, sino además las consecuencias positivas e intangibles que esos bienes generan en la existencia del hombre — su

* Abogado de la Pontificia Universidad Javeriana; magíster en Derecho de la Empresa y de los Negocios de la Universidad de Barcelona (España). Miembro del Grupo de Investigación en Derecho Privado de la Facultad de Ciencias Jurídicas de la Pontificia Universidad Javeriana; coautor del libro Solidarismo contractual. El deber de cooperación y su repercusión en la responsabilidad civil y autor de artículos investigativos publicados en revistas como Vniversitas, Universitas Estudiantes y Elementos de Juicio; columnista del periódico Ámbito Jurídico. Correo electrónico: fpz14@hotmail.com 
tranquilidad, su dignidad, la garantía de supervivencia-, lo que podría denominarse corolarios y/o derechos inmateriales dela naturaleza.

Cuando se trata de resguardar los mencionados derechos ecológicos - patrimoniales y extrapatrimoniales - desde el ámbito del derecho civil y en particular la responsabilidad civil, la pregunta que muchos se formulan es: qué tiene que ver el derecho civil con el ambiente, máxime cuando estos últimos, primero, se tratan de derechos de estirpe preponderantemente colectiva; segundo, su protección, especialmente inmaterial, le ha correspondido históricamente al derecho público; y, tercero, la legislación decimonónica del derecho civil no le otorga una defensa clara y concreta.

En efecto, aunque los derechos ambientales son por naturaleza colectivos, es claro, para un importante sector doctrinal, que el derecho público es insuficiente para salvaguardar al medio natural, más aún, para resarcir los daños individuales derivados del perjuicio ambiental — los denominados daños ambientales impuros- A la luz de ello, la jurisprudencia colombiana en materia de responsabilidad civil, gracias a la cláusula general de responsabilidad, bajo el artículo 2341 del Código Civil (cc), así como algunas disposiciones especiales que se acercan a la materia ambiental dentro del ordenamiento común, artículos 2356 del cc, ha reconocido la responsabilidad civil ambiental, que se encamina a proteger preponderantemente los intereses privados e intrínsecamente los colectivos.

De esta manera los daños extrapatrimoniales o no patrimoniales de carácter individual adquieren una vital relevancia en la medida en que su protección se dirige no solo a garantizar las haciendas particulares de la víctima, sino también a salvaguardar, interior e indirectamente, los de la colectividad, presentes y futuros, a propósito de completar la defensa que presta el ordenamiento jurídico al ambiente.

A sabiendas de la trascendencia humana que envuelve la materia y ubicándose desde el ámbito jurídico civil,interesa bajo este artículo aproximarse, a manera de invitación, al análisis de los daños no patrimoniales de carácter individual que se generan como consecuencia de la transgresión al medio natural. Para ese efecto, primero, se abordarán someramente los elementos más característicos de la responsabilidad civil ambiental, con el objetivo de ubicarse en el estudio propuesto. En segundo lugar, a la luz de la jurisprudencia y la doctrina, se propondrán los conceptos de daño no patrimonial y daño ambiental, para efectos de establecer, dentro del ordenamiento civil, su fuente 
y características más relevantes. Por último, en la tercera parte, se examinarán sucintamente los presupuestos específicos que configuran la compensación del daño ambiental.

\subsection{Breve referencia a la responsabilidad civil ambiental}

A modo ilustrativo y de ubicación, se pasan a dar unos breves lineamientos acerca de la responsabilidad civil ambiental en Colombia.

Es importante empezar por afirmar que el papel que hoy juega la responsabilidad civil en la protección del ambiente es residual, ya que su finalidad es la de resolver los conflictos entre particulares y, en consecuencia, conforme a sus intereses privados (Díez-Picazo, 2011, p. 432).

En ese sentido, mediante el título de responsabilidad civil ambiental se estructura el tipo de responsabilidad a la que habrán de enfrentarse aquellos sujetos que, por medio de la creación de riesgos ambientales, causen un daño a las personas —en sus bienes y/o intimidad-, así como al equilibrio ecológico. Por esa razón destaca Díez-Picazo que

[s]e deben diferenciar los daños por contaminación de los daños estrictamente ecológicos, porque las soluciones válidas para los unos no lo son para los otros. De este modo, por daño por contaminación, debemos entender aquellas lesiones patrimoniales y morales, que $\mathrm{co}^{-}$ mo consecuencia de un accidente ambiental afectan a la persona y a sus bienes. Daños ecológicos, por su parte, son aquellos sufridos por el medio ambiente que, como consecuencia de un accidente causado por la mano del hombre, afectan a su equilibrio natural (2011,p.432).

Así, el derecho civil, por intermedio de la responsabilidad civil ambiental, establece los criterios y presupuestos de la responsabilidad derivada de los daños por contaminación — tanto patrimoniales como extrapatrimoniales- que se le causan a una persona in concreto. Sin embargo, de manera indirecta y más bien con poca demostración práctica, como lo han vislumbrado los enfoques del igualitarismo ecológico (ecological egalitarianism) o ecologismo profundo (deepecology), la responsabilidad civil ambiental se dirige en cierta medida hacia la protección del medio ambiente como titular de derechos (Ruda González, 2008, p. 46; Cabanillas Sánchez, 1996, pp. 39 y ss.; sccsJ, sentencia del 14 de octubre de 2011, p.30). 
En esa línea, la Sala de Casación Civil de la Corte Suprema de Justicia de Colombia (sccsj), amparada en doctrina especializada, determina que el daño ambiental, que interesa a la responsabilidad civil dentro del derecho privado, es el que se ha conocido e identificado con el apelativo de daño ambiental impuro, ya que se trata del detrimento consecuencial, indirecto o consecutivo de otros derechos, bienes o intereses particulares a consecuencia del quebranto al ambiente, y cuyo titular no es la colectividad in abstracto, sino una, o varias, o muchas personas individualmente consideradas (sccsJ, sentencia del 16 de mayo de 2011). Se verá con mayor detenimiento en un acápite posterior.

Ahora bien, como lo identifica Tamayo Jaramillo, es posible que la contaminación ambiental dé lugar a una responsabilidad de tipo contractual. No obstante, son mucho más frecuentes las hipótesis de contaminación ambiental que se enmarcan dentro de los presupuestos de la responsabilidad extracontractual (Tamayo Jaramillo, 2007, p. 644). De ahí que este acápite de presentación se centre en esta última temática, que podría considerarse de mayor interés a la luz del asunto que se propone abordar.

Así las cosas, la responsabilidad civil extracontractual en materia ambiental, como lo ha establecido la jurisprudencia nacional (sccsj, sentencia del 16 de mayo de 2011, sentencia del 30 de abril de 1976, cLII, pp. 111 y ss.), tiene su fundamento primigenio en el artículo $2356 \mathrm{del} \mathrm{cc}^{1} \mathrm{y}$, en consecuencia, se sitúa dentro del régimen jurídico de las actividades peligrosas en virtud del riesgo congénito a la acción u omisión dañosa que, aunque puedan ser lícitas, útiles y necesarias, no autorizan a generar perjuicios a los demás.

No distante del precepto normativo común señalado, se encuentra el artículo 16 de la Ley 23 de 1973, la cual sirvió como fundamento al Código de Recursos Naturales expedido en 1974 —Decreto 2811—, que establece

\footnotetext{
${ }^{1}$ Es importante destacar que la disposición normativa señalada no es la única que fundamenta toda la estructura de la responsabilidad civil extracontractual en materia ambiental dentro del ordenamiento jurídico colombiano. En efecto, es dable encontrar otras normas que sostienen, de una parte, la protección del medio ambiente y, de la otra, los derechos de las personas frente a este, preponderantemente en el ámbito civil. Así las cosas, cabe mencionar: i) el artículo 88 de la Constitución Política de Colombia de 1991; ii) el artículo 2341 del cc, en casos de responsabilidad por incumplimiento de normas ambientales; iii) el artículo 669, en los eventos de responsabilidad civil derivada del derecho de dominio; y iv) el Código de Recursos Naturales (Tamayo Jaramillo, 2007).
} 
una responsabilidad objetiva a cargo del Estado y de los particulares cuando alguno de ellos atente contra el patrimonio colectivo de los recursos naturales. ${ }^{2}$

En ese sentido, ha dicho nuestra sccsj que bajo este régimen “[ $[.$.$] basta$ demostrar el daño y la relación de causalidad para obtener la reparación 'del perjuicio sufrido, salvo prueba de fuerza mayor, o caso fortuito o de la culpa exclusiva de la propia víctima', [...]"(sccsJ, sentencia del 16 de mayo de 2011).

Así, quien responde es el guardián, como acontece en los demás supuestos de la responsabilidad por actividades peligrosas, en la medida en que tiene el poder intelectual de control y dirección de la acción. Ahora, "[...] puede suceder que no sólo el dueño de la actividad contaminante sea su guardián sino que dicho poder se encuentre, también, en cabeza de un tercero, en cuyo caso, ambos serán responsables solidariamente" (Tamayo Jaramillo, 2007, p. 646).

Por último, merece hacerse una brevísima referencia a la teoría del abuso del derecho como fuente de responsabilidad. De esta forma, cuando se prueba que la causa del daño ambiental es el comportamiento abusivo, bien en forma culposa o dolosa, por parte del dueño de la actividad contaminante, lo aplicable es la responsabilidad con culpa probada de que trata el artículo 2341 del cc (Tamayo Jaramillo, 2007, p. 647; Mazeaud, Tunc y Chabas, 1965). En consecuencia, bajo esta modalidad de responsabilidad se requiere, a diferencia de la actividad peligrosa, que el demandante acredite cada uno de los elementos constitutivos de responsabilidad — culpa, daño y nexo causal—, particularmente el atinente al de la culpa, sin la cual no puede atribuirse responsabilidad civil ambiental por la vía de la teoría del abuso del derecho.

\subsection{El daño extrapatrimonial en el derecho del medio ambiente}

Para tratar la temática que se pretende bajo este acápite, se estima preciso, primero, aproximarse a los conceptos de daño no patrimonial y daño ambiental, para luego, y en segundo lugar, adentrarse a la noción y características más relevantes del perjuicio extrapatrimonial de carácter ambiental.

\footnotetext{
${ }^{2}$ En los siguientes términos se expresa el señalado artículo 16 de la Ley 23 de 1973, "por el cual se conceden facultades extraordinarias al Presidente de la República para expedir el Código de Recursos Naturales y de Protección al Medio Ambiente y se dictan otras disposiciones": "Artículo 16. El Estado será civilmente responsable por los daños ocasionados al hombre o a los recursos naturales de propiedad privada como consecuencia de acciones que generan contaminación o detrimento del medio ambiente. Los particulares lo serán por las mismas razones y por el daño o uso inadecuado de los recursos naturales de propiedad del Estado".
} 
El concepto de daño extrapatrimonial o no patrimonial. Como enseña la sccsJ,

[...] el daño podrá recaer sobre bienes susceptibles per sede evaluación pecuniaria inmediata u objetiva o respecto de "intereses que según la conciencia social no son susceptibles de valorización económica" (Bianca,1999: 166), esto es, afectar valores vitales, consustanciales, inmanentes e intrínsecos del sujeto, inherentes a su personalidad y esfera afectiva, ora extrínsecos y externos al mismo, es decir, ostentar naturaleza material (Dommages matériels), ora inmaterial (Dommages immatériels), bien patrimonial (Vermögensschaden), ya extrapatrimonial (nicht Vermörgensschaden) (sccsj, sentencia del 18 de septiembre de 2009).

En ese sentido, son innumerables, así como diversas, las definiciones que se le han ofrecido al daño no patrimonial. Es más, un sector importante de la doctrina ha igualado, de antaño, los conceptos de daño extrapatrimonial y daño moral lato sensu3 (Mazeaud, Mazeaud y Tunc, 1961, p. 423). Al respecto explica De Ángel Yágüez que "[1] os llamados daños morales son los infligidos a las creencias, los sentimientos, la dignidad, la estima social o la salud física; en suma, a los que se suelen denominar derechos de la personalidad o extrapatrimoniales" (1993, p. 675).

Sin perjuicio de la dificultad de limitación de los conceptos, "[e]1 daño no patrimonial no puede ser definido más que en contraposición al daño patrimonial. Daño no patrimonial, en consonancia con el valor negativo de su misma expresión literal, es todo daño privado que no puede comprenderse en el daño patrimonial, por tener por objeto un interés no patrimonial, o sea, que guarda relación a un bien no patrimonial" (De Cupis, 1975, p. 122).

De esta manera, la patrimonialidad es el atributo distintivo del daño bajo la categoría que se estudia y, en consecuencia, se refiere, siguiendo a De Cupis, a una necesidad de carácter económico, por lo que patrimonial es, in concreto, cualquier bien exterior respecto de la persona, que tenga el atributo

\footnotetext{
${ }^{3}$ Se ha entendido así porque, como se sabe, en la actualidad existe una gran proliferación de daños extrapatrimoniales - daño a la salud, vida en relación, entre otros-, reconocidos por la doctrina y la jurisprudencia, que amplían el espectro de los llamados, in extenso, daños morales (De Cupis, 1975, pp. 122 y ss.).
} 
de clasificarse dentro de la riqueza material, esto es, valorable en dinero, e idóneo para satisfacer una necesidad económica (1975, p. 121). Por ende, cuando se trata de daños extrapatrimoniales, se describe y delimita a aquella serie de perjuicios causados al sujeto que no tienen ni cumplen una necesidad de tipo económico y que, por efecto, son de difícil tasación y resarcimiento.

El concepto de daño ambiental. De forma muy concreta, por daño ambiental puede entenderse el menoscabo o perjuicio que sufre el medio ambiente. A partir de esta concepción escueta e inicial, surgen dos preguntas trascendentales a propósito de abordar con mayor suficiencia la noción objeto de análisis dentro del derecho y, particularmente, dentro del ámbito de la responsabilidad civil, a saber: i) ¿qué se entiende por medio ambiente? y ii) ¿cuál detrimento ambiental es el que interesa o protege la responsabilidad civil?

Ahora bien, sin perjuicio de las acepciones legales, "[...] por medio ambiente se puede entender el entorno que rodea al hombre y que está integrado por el agua, el aire, el suelo, la fauna, la flora y el paisaje, y cuya alteración influye en la vida y desarrollo humano, ya que afecta no sólo a las condiciones favorables para la conservación de su salud, sino también a su calidad de vida" (Yanguas Montero, 2006, p. 36).

ii) El daño ambiental que importa a la responsabilidad civil. Como enseña la sccsJ,

${ }_{4}^{4}$ i) El medio ambiente. En Colombia, a diferencia de lo que acontece en otros ordenamientos como el español, se encuentran definidos, por el derecho positivo, los conceptos atinentes al medio ambiente y su detrimento. Así, a la luz del artículo $2^{\circ}$ de la Ley 23 de 1973 — por el cual se conceden facultades extraordinarias al Presidente de la República para expedir el Código de Recursos Naturales y de Protección al Medio Ambiente y se dictan otras disposiciones—, "[...] el medio ambiente está constituido por la atmósfera y los recursos naturales renovables". Por su parte, la contaminación ambiental, definida en el artículo 4 de la Ley 23 de 1973 (ver también el artículo 8 del Decreto 2811 de 1974 —por el cual se dicta el Código Nacional de Recursos Naturales Renovables y de Protección al Medio Ambienteque la define en términos muy similares ), es "[...] la alteración del medio ambiente por sustancias o formas de energía puestas allí por la actividad humana o de la naturaleza, en cantidades, concentraciones o niveles capaces de interferir con el bienestar y la salud de las personas, atentar contra la flora y la fauna, degradar la calidad del medio ambiente o afectar los recursos de la nación o de particulares"; y, por daño ambiental, en lo atinente a la fijación de las tasas retributivas, siguiendo lo dispuesto en el artículo 42 de la Ley 99 de 1993 — por la cual se crea el Ministerio del Medio Ambiente, se reordena el sector público encargado de la gestión y conservación del medio ambiente y los recursos naturales renovables, se organiza el Sistema Nacional Ambiental (sina) y se dictan otras disposiciones-, "[...] el que afecte el normal funcionamiento de los ecosistemas o la renovabilidad de sus recursos y componentes; [...]" (sccsj, sentencia del 16 de mayo de 2011). 
[... el daño ambiental en rigor recae sobre el ambiente, esto es, un valor, interés o derecho público colectivo, supraindividual o más allá del individuo, cuyo titular es la colectividad en general, no un particular, ni sujeto determinado, o sea, el quebranto afecta no a una, sino a todas las personas, y “exclusivamente el medio natural en sí mismo considerado, es decir, las 'cosas comunes' que en ocasiones hemos designado como 'bienes ambientales', tales como el agua, el aire, la flora y la fauna salvaje. Se trata entonces de aquello que se ha convenido llamar 'perjuicios ecológicos puros" (Viney y Jourdain, 1998, p. 55; a la locución 'daño ambiental puro' refiere la Ley 491 de 1999, artículo $2^{\circ}$, inciso 2, respecto del 'seguro ecológico') (sccsj, sentencia del 16 de mayo de 2011).

Aunque el daño ambiental es por naturaleza colectivo, en la medida en que lastima a los bienes ambientales de provecho general, también puede generar lesiones directas o indirectas a los intereses individuales de los particulares.

Así, la doctrina y la jurisprudencia han distinguido, como se ha visto, al daño ambiental puro, menoscabo que se le infringe exclusivamente al medio natural, del llamado daño ambiental impuro, atinente al "[...] detrimento consecuencial, conexo, reflejo, indirecto o consecutivo de otros derechos, bienes o intereses particulares a consecuencia del quebranto al ambiente, y cuyo titular no es la colectividad in abstracto, sino una, o varias, o muchas personas individualmente consideradas" (sccsj, sentencia del 16 de mayo de 2011; Luquin Bergareche, 2005, pp. 136 y ss.).

Es precisamente esta última categoría, la del daño ambiental impuro, la que interesa a la responsabilidad civil a efectos de resarcir los perjuicios ocasionados. En efecto, como indica Yanguas Montero, "[d]esde una óptica privatística, sólo son relevantes los daños que, degradando el medio ambiente, perjudican a un interés particular" (Yanguas Montero, 2006, p. 37; Álvarez Lata, 2002, p. 777; Drago, 1974, p. 13).

Ahora bien, sin perjuicio del entendimiento anterior, al que se suman tratadistas como Reyes López (2001, p. 214), Macías Castillo (2004, p. 202) y Prieur (1991, p. 729), para otro sector doctrinal solo merecen el calificativo de ambientales aquellos perjuicios ecológicos que exceden de los intereses 
individuales y de los que se encarga el derecho público 5 (Jordano Fraga,2001, p. 287; Conde Antequera, 2004, p. 26). Esta misma comprensión parece tenerla nuestra sccsj, quien, bajo la tan relevante sentencia del 16 de mayo de 2011, considera que

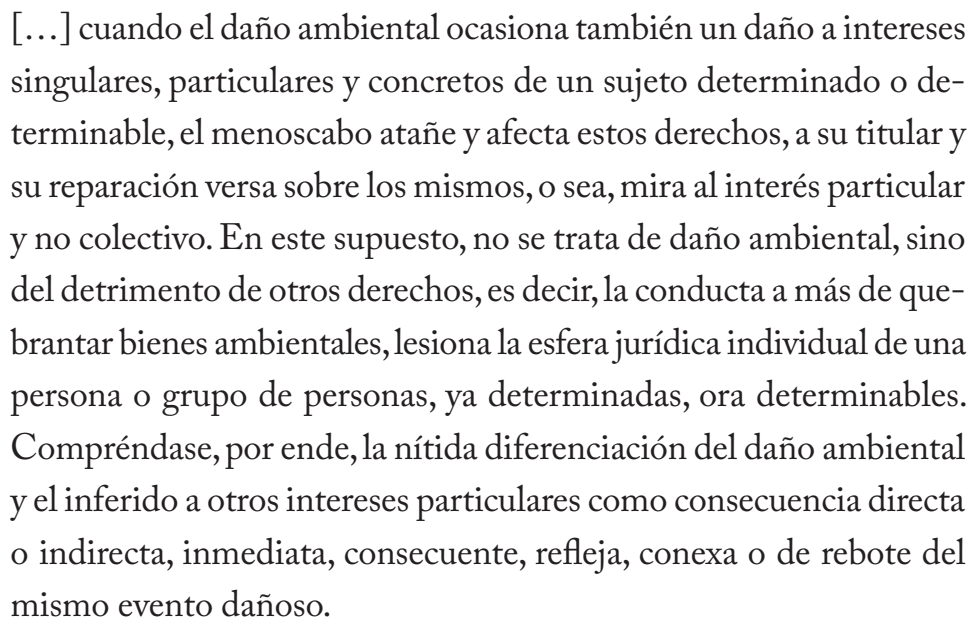

Conforme a lo dicho hasta aquí, el perjuicio ambiental relevante para la responsabilidad civil es aquel que, afectando al medio natural, menoscaba de forma directa o indirecta los derechos individuales de la persona. En consecuencia, la denominada responsabilidad civil ambiental, tras la vulneración de tales derechos, procura resarcirlos.

Hacia la noción y características del daño extrapatrimonial ambiental en el campo de la responsabilidad civil. A la luz de lo analizado en las líneas precedentes, el daño no patrimonial ambiental puede ser definido como el detrimento o perjuicio que afecta los bienes inmateriales de la persona como consecuencia de una alteración al medio ambiente. Sus requisitos y/o características no distan de las que la doctrina y la jurisprudencia le han reconocido a los daños en general (Yanguas Montero, 2006, p. 61; Corte Suprema de Justicia, Sala de Negocios Generales, sentencia del 27 de septiembre de 1946, sentencia del 29 de agosto de 1960). Así, son particularidades del daño extrapatrimonial

\footnotetext{
5 "Según esta concepción, no puede aplicarse el calificativo de ambientales ni revisten ningún tipo de especialidad los perjuicios que, aunque se originen como consecuencia de la alteración de un elemento del medio ambiente, afectan a intereses particulares" (Yanguas Montero, 2006, pp. 38 y 39).
} 
ambiental las siguientes, entre otras tantas que la doctrina ha identificado (Pérez Fuentes, 2009, pp. 36 y 37).

a) Cierto. Este atributo del daño ha sido explicado por la sccsj en los siguientes términos:

[E]n tratándose del daño, (...) la indemnización exige la certeza del detrimento, o sea, su verdad, existencia u ocurrencia tangible, incontestable o verosímil, ya actual, ora ulterior, acreditada por el demandante como presupuesto ineluctable de la condena con pruebas idóneas en su entidad y extensión. La certidumbre del daño, por consiguiente, es requisito constante ineludible de toda reparación y atañe a la real, verídica, efectiva o creíble conculcación del derecho, interés o valor jurídicamente protegido, ya actual, bien potencial e inminente, mas no eventual, contingente o hipotética (Cas. Civ., sentencias del 11 de mayo de 1976, 10 de agosto de 1976, G.J. 2393, pp. 143 y 320) (sccsj, sentencia del 9 de septiembre de 2010).

Así, la certeza del daño extrapatrimonial ambiental implica la necesidad de que el resultado lesivo sea objetivamente efectivo, presente o futuro, en cualquiera de los derechos y/o bienes inmateriales de la persona afectada.

b) Inmediato o directo. El carácter inmediato o directo del daño hace alusión, en realidad, al nexo de causalidad —elemento constitutivo de responsabilidad- (De Cupis, 1975, p. 247; Ternera Barrios y Ternera Barrios, 2008). De este modo, y dentro del ámbito objeto de análisis, debe existir una relación de causalidad —-fenómeno jurídico de causa y efecto- entre el daño ecológico y el daño extrapatrimonial acusado. En otras palabras, el perjuicio inmaterial o material que padece la persona debe ser consecuencia seguida, conexa del hecho dañoso ambiental (sccsj, sentencia del 16 de mayo de 2011).

c) Antijurídico. E1 daño debe ser ilícito, esto es, no estar conforme a los mandamientos y lineamientos dispuestos en el ordenamiento jurídico. ${ }^{6} \mathrm{De}$

\footnotetext{
6 "En nuestro ordenamiento jurídico se ha planteado la cuestión de si la antijuridicidad constituye un requisito de responsabilidad civil extracontractual, siendo mayoritaria la opinión de quienes consideran que el comportamiento que engendra la obligación de reparar un daño ha de ser antijurídico o ilícito. Desde otra perspectiva, se ha mantenido, de forma acertada a nuestro juicio, que el problema no estriba en calificar como ilícita la actividad inicial de la que el daño pueda ser resultado, ya que hasta que el daño no se produzca no hay nada que indemnizar. Lo que hay que determinar, por tanto, no es la
} 
este modo, el daño que afecta los bienes jurídicos inmateriales de la víctima debe a su vez transgredir las normas ambientales en el caso específico de que se trate.

Ahora, íntimamente ligado al concepto de antijuridicidad, se encuentra el asunto relativo a la tolerabilidad del daño. Así, en el campo de análisis, “[a]1 daño ambiental que excede la esfera patrimonial se le exige que sea intolerable, ya que si no merece esta consideración, no surgirá la responsabilidad y, por lo tanto, no será susceptible de indemnización por cuanto no será considerado antijurídico. Esta exigencia implica que no puedan derivarse daños resarcibles de las situaciones de mera molestia, aburrimiento, enojo o enfado"7 (Yanguas Montero, 2006, p. 131; Cabanillas Sánchez, 1996, p. 145).

\subsection{La compensación del daño extrapatrimonial en el derecho del medio ambiente}

En Colombia, al igual que en otros ordenamientos, como el español, la reparación de los daños extrapatrimoniales ha encontrado asidero normativo en la cláusula general de responsabilidad civil, artículo 2341 del cc.

Así, una vez cumplidos los requisitos constitutivos de la responsabilidad civil ambiental, surge la obligación de indemnizar y/o compensar los daños causados.

De este modo, dentro del campo de la compensación del daño no patrimonial derivado del perjuicio al medio ambiente, se plantean varias cuestiones

conformidad con el ordenamiento jurídico de una conducta — hay actos perfectamente acordes con el derecho positivo, tales como el desarrollo de un actividad fabril, de los que nadie duda que pueda surgir responsabilidad - sino si los daños en sí mismo considerados son o no lícitos. Puede, en consecuencia, afirmarse que la ilicitud constituye una característica del daño resarcible"(Yanguas Montero, 2006,pp. 129 y 130; Cabanillas Sánchez, 1992). "Si resulta necesario, para obtener reparación del atentado contra los sentimientos afectivos, justificar un pesar real y profundo, todos los que experimenten tal pena no son admitidos a alegarlo ante la justicia. De igual modo que nadie puede pedir reparación del daño material que sufre él cuando el interés lesionado no fuere 'legítimo', así tampoco puede ser invocado el pesar más que si surge de la ruptura de una situación 'legítima'; es decir, conforme a la ley y a la moral” (Mazeaud, Mazeaud y Tunc, 1961, p. 463).

${ }^{7}$ Es importante destacar la enorme dificultad y problemática que enmarca el hecho de establecer el límite de la tolerabilidad, el cual una vez sobrepasado permite que los perjuicios sean resarcidos o compensados. Sin perjuicio de ello, Yanguas propone algunos lineamientos a efectos de determinar la tolerabilidad del daño. Así lo explica: "[...] para determinar si un daño es o no tolerable, se ha de atender a la entidad del daño (aunque en ocasiones se examina la entidad de la propia acción generadora del daño), a la conciencia social y a los criterios relativos a las circunstancias de cada caso"(Yanguas Montero, 2006, p. 136). 
jurídicas de suma trascendencia, de las cuales podemos resaltar: i) los modos de reparar los daños - pecuniaria y en especie o in natura - ; yi) la valoración del daño extrapatrimonial.

i) Los modos de reparar los daños. Como bien se sabe, la función primordial de la responsabilidad civil es la de lograr que el perjudicado quede indemne de los daños sufridos.

Aun así, los artículos 2341 y siguientes del cc, reguladores de la responsabilidad civil, no determinan el cómo o la manera en que debe realizarse dicha indemnización. En consecuencia, y para ello, se han planteado dos formas distintas: la reparación a través del mismo bien u objeto dañado - reparación en especie, in natura o específicay la reparación por medio de la entrega de una suma de dinero al agraviado — reparación por equivalente o pecuniaria-. Como explica Yanguas, "[...] la reparación en especie es aquella que tiene por finalidad reponer al perjudicado a un estado igual al que poseía antes de que se produjera la causación del perjuicio, pudiendo realizarse, en la práctica, por medio de actividades constitutivas de un dare o de un facere. Implica, por tanto, la puesta en práctica de la actividad precisa para reponer lo dañado al estado en que se encontraba con anterioridad al daño" (Yanguas, 2006, p. 196). Cuando la reparación in natura resulte excesivamente gravosa para el causante del daño o no sea posible, se confiere una cantidad económica. De esta forma, bajo la reparación equivalente, no se reintegra el objeto lesionado a su estado inicial u original, sino que se le sustituye por un semejante pecuniario.

Ahora bien, a sabiendas de lo anterior, en el ámbito de la reparación de los daños derivados del menoscabo ambiental, se ha entendido que, en la medida de las posibilidades, debe imponerse la indemnización in natura, ya que debe prevalecer la restitución de las cosas a su estado original. Sin embargo, esta alternativa no siempre es posible. Comúnmente en las hipótesis en las que se generan perjuicios ambientales, y muy especialmente de carácter extrapatrimonial (piénsese, a manera de ejemplo, en los ruidos provenientes de una fábrica que no deja dormir a las personas de un barrio), no cabe la reparación en especie o in natura, de una parte, porque, como se anticipaba, el 
bien objeto de la trasgresión no permite retrotraer los efectos a su estado inicial, o porque, de la otra, la reparación in natura resulta excesivamente gravosa para el causante del daño. Estas situaciones, presentes con mucha frecuencia, hacen que deba acudirse a la indemnización pecuniaria por ser el único método para compensar el daño sufrido por el lesionado. En definitiva, la compensación económica se vuelve la forma más común de reparación del daño extrapatrimonial derivado del perjuicio al ambiente (Yanguas, 1996, pp. 196 y ss.).

ii) La valoración del daño extrapatrimonial. A sabiendas que desde el punto de vista práctico prima, para la reparación de los daños no patrimoniales emanados del menoscabo a la naturaleza, la concesión de una indemnización — reparación equivalente- sobre la reparación in natura o en especie, se hace necesario establecer el valor, a propósito de resarcir los perjuicios causados. De esta manera, sobresale tal vez el asunto que reviste mayor dificultad dentro del análisis del daño no patrimonial en general, el relativo a su estimación o cuantificación pecuniaria.

Así, la doctrina y la jurisprudencia han establecido dos criterios y/o elementos, íntimamente atados, para determinar el valor de la compensación: las bases y el quantum indemnizatorio. Ello en la medida en que en nuestro ordenamiento civil no existen lineamientos generales establecidos que permitan la cuantificación de los perjuicios ambientales y extrapatrimoniales, por lo cual, se reitera, la valoración constituye una materia de especial complejidad al concurrir factores de política legislativa, seguridad jurídica, justicia material y otros tantos no menos importantes relacionados con la técnica legal (Yanguas, 1996, pp. 202 y 203; García López, 1990, p. 150; De Ángel Yágüez, 1989 , p. 50).

En el ámbito colombiano, siguiendo el estudio realizado por Isaza Posse, el Consejo de Estado de Colombia ha considerado, en lo que refiere a la indemnización y tasación de los perjuicios no patrimoniales, que

[...] "hay lugar a indemnizar todo perjuicio moral sin importar su origen, inclusive el derivado de la pérdida de bienes materiales o el causado con el incumplimiento de las obligaciones derivadas del 
contrato, siempre que, como sucede en relación con toda clase de perjuicios, aquellos sean demostrados en el proceso". Para que haya lugar a la reparación del perjuicio basta que el padecimiento sea fundado, sin que se requiera acreditar ningún requisito adicional. Corresponde al juez tasar discrecionalmente la cuantía de su reparación, teniendo en cuenta las condiciones particulares de la víctima y la gravedad objetiva de la lesión. La intensidad de daño es apreciable por sus manifestaciones externas, por esto se admite para su demostración cualquier tipo de prueba (Consejo de Estado colombiano, sentencia de la Sección Tercera del 5 de diciembre de 2006; Isaza Posse, 2009, pp. 45 y ss.).

La sccsj ha establecido algunos montos y baremos aplicables para la compensación de los daños extrapatrimoniales in extenso (scCSJ, sentencia del 7 de septiembre de 2001, sentencia del 30 de junio de 2005, sentencia del 20 de enero de 2009). Sin perjuicio de ello, cabe resaltar que la reparación de los daños extrapatrimoniales derivados del daño ambiental no ha sido un tema suficientemente tratado por la jurisprudencia colombiana. De ahí que se pueda concluir, a luz de lo indicado por el Consejo de Estado patrio y la doctrina, que, para efectos de restituir al dañado, el juzgador deberá establecer, con fundamentos en las pruebas que acrediten la gravedad objetiva de la lesión y las condiciones de la víctima - las bases-, el monto o valor de la compensación -quantum-.

\section{Bibliografía}

Álvarez Lata, N. (2002). El daño ambiental. Presente y futuro de su reparación. Revista de Derecho Privado.

Bianca, C. (1999). Diritto civile: la responsabilità. Milán: Giuffrè.

Cabanillas Sánchez, A. (1992). La responsabilidad por daños ambientales según la jurisprudencia civil. En Estudios de derecho civil en homenaje al profesor Dr. José Luis Lacruz Berdejo. Barcelona: Bosch.

Cabanillas Sánchez, A. (1996). La reparación de los daños al medio ambiente. Pamplona: Editorial Aranzadi.

Colombia, Consejo de Estado, Sección Tercera. Sentencia del 5 de diciembre de 2006. Expediente 16.347.

Colombia, Corte Constitucional. Sentencia C-632 de 2011. 
Colombia, Corte Suprema de Justicia, Sala de Casación Civil. Sentencia del 7 de septiembre de 2001. Expediente 6171.

Colombia, Corte Suprema de Justicia, Sala de Casación Civil. Sentencia del 30 de junio de 2005. Expediente 68001-3103-005-1998-00650.01.

Colombia, Corte Suprema de Justicia, Sala de Casación Civil. Sentencia del 20 de enero de 2009. Expediente 17001310300519930021504.

Colombia, Corte Suprema de Justicia, Sala de Casación Civil. Sentencia del 18 de septiembre de 2009. Referencia: 20001-3103-005-2005-00406-01.

Colombia, Corte Suprema de Justicia, Sala de Casación Civil. Sentencia del 9 de septiembre de 2010. Referencia: 17042-3103-001-2005-00103-01.

Colombia, Corte Suprema de Justicia, Sala de Casación Civil. Sentencia del 16 de mayo de 2011. Referencia: 52835-3103-001-2000-00005-01.

Colombia, Corte Suprema de Justicia, Sala de Casación Civil. Sentencia del 14 de octubre de 2011. Referencia: C-6800131030032005-00277-01.

Colombia, Corte Suprema de Justicia, Sala de Negocios Generales. Sentencia del 27 de septiembre de 1946.

Colombia, Corte Suprema de Justicia, Sala de Negocios Generales. Sentencia del 29 de agosto de 1960.

Colombia, Corte Suprema de Justicia, Sala de Negocios Generales. Sentencia del 30 de abril de 1976, cLiI.

Conde Antequera, J. (2004). El deber jurídico de restauración ambiental. Granada: Editorial Comares.

De Ángel Yágüez, R. (1993). Tratado de responsabilidad civil. Madrid: Civitas.

De Cupis, A. (1975).El daño. Teoría general de la responsabilidad civil. Barcelona: Editorial Bosch.

Díez-Picazo, L. (2011). Fundamentos del derecho civil patrimonial. V.La responsabilidad civil extracontractual. Pamplona: Editorial Civitas, Thomson Reuters.

Drago, R. (1974). Prefacio a la obra de Girod, P. La réparation du dommage écologique. París: Editorial LGDJ.

Isaza Posse, M. (2009).De la cuantificación del daño, manual teórico-práctico. Bogotá: Editorial Temis.

Jordano Fraga, J. (2001). Administración y responsabilidad por daños al medio ambiente: la construcción del régimen jurídico de los daños ambientales. Madrid: Editorial Escuela Judicial Consejo General del Poder Judicial.

Luquin Bergareche, R. (2005). Mecanismos jurídicos civiles de tutela ambiental. Navarra: Thomson Aranzadi. 
Macías Castillo,A. (2004). El daño causado por el ruido y otras inmisiones. Madrid: La Ley.

Mazeaud,H., Mazeaud, L., \& Tunc, A. (1961). Tratado teórico y práctico de la responsabilidad civil delictual y contractual. T. I, Vol. I. Buenos Aires: Editorial Ediciones Jurídicas Europa-América.

Pérez Fuentes, G. (2009). La responsabilidad civil por daños al medio ambiente en el derecho comparado. Revista Prolegómenos, 12(23), 35-42.

Prieur, M. (1991). Droit de l'environnement. Paris: Editorial Dalloz.

Reyes López, M.J.(2001).Derecho ambiental español. Valencia:Tirant lo Blanch. Ruda González, A. (2008). El daño ecológico puro. La responsabilidad civil por el deterioro del medio ambiente, con especial atención a la Ley 26/2007, de 23 de octubre, de responsabilidad medioambiental. Pamplona: Thomson Aranzadi.

Tamayo Jaramillo, J. (2007).Las acciones constitucionales contra la contaminación ambiental en el derecho colombiano: responsabilidad civil. Bogotá: Editorial Rubinzal-Culzoni.

Ternera Barrios, L., \& Ternera Barrios, F. (2008). Breves comentarios sobre el daño y su indemnización. Revista Opinión Jurídica, 7(13).

Viney, G., \& Jourdain, P. (1998). Traité de droit civil. Les conditions de la responsabilité. Paris: LGDJ.

Yanguas Montero, G. (2006). El daño no patrimonial en el derecho del medio ambiente. Pamplona: Thomson Civitas. 